\title{
Parque Ecológico Metropolitano: \\ Una Propuesta PARA LA \\ CIUdAd de BarRanquilLa
}

\section{Metropolitan Ecological Park: A Proposal for the Barranquilla City}

DOI: 10.17981/mod.arq.cuc.18.2.2018.05

Fecha de Envío: 13/09/2018 Fecha de Aceptación: 11/09/2018

\section{Jose Cesar Crissien Barbosa}

Universidad de la Costa, CUC (Colombia)

jcrissie2@cuc.edu.co

Para citar este artículo:

Crissien, J. (2018). Parque Ecológico Metropolitano: Una Propuesta para la Ciudad de Barranquilla. MODULO ARQUITECTURA-CUC, vol. 21, no. 1, pp. 131-160. DOI: 10.17981/mod.arq.cuc.18.2.2018.05

\section{Resumen}

El presente artículo constituye un esfuerzo y una contribución que ante todo busca generar un elemento clave en el fomento del espacio público para la ciudad de Barranquilla. El proyecto plantea generar espacios con un gran potencial de aprovechamiento ecológico debido a que gran parte del área presenta condiciones de riesgo no mitigable, lo cual reduce las posibilidades de buscar el máximo resultado desde el punto de vista del desarrollo urbano. Ello es lo que impulsa a balancear el conjunto de acciones que ante todo estarán enmarcadas en el marco teórico de la sustentabilidad ambiental y la preservación ecológica manifiesta en los diferentes espacios tanto de carácter público como de recreación, cultura y lúdica ambiental para el disfrute de todos. El principal instrumento que se constituye en punta de lanza es el POT recientemente aprobado y los diferentes instrumentos y análisis que de él surgen.

Palabras clave: espacio público, diseño urbano, ecología urbana, sustentabilidad, plan zonal, unidad de actuación urbanística.

\begin{abstract}
This final degree is an effort and contribution that primarily seeks to generate a key element in promoting public space for the city of Barranquilla. The project proposes to create spaces with great potential ecological advantage because much of the area has not mitigated risk conditions, which reduces the possibilities of seeking the maximum result from the point of view of urban development. This is what drives balance the set of actions that primarily will be framed within the theoretical framework of environmental sustainability and ecological preservation manifested in different spaces both public and recreation, culture and fun environment for all to enjoy. The main instrument is the spearhead is the recently approved POT and the different tools and analysis that arise from it.
\end{abstract}

Keywords: urban design, public space, urban ecology, sustainability, urban partial planning, urban unit activity. 


\section{INTRODUCCIÓN}

Diversas investigaciones ligadas al comportamiento social y calidad de vida del hombre en ambientes urbanos, han demostrado que las áreas verdes urbanas tienen una influencia benéfica en la salud y el bienestar de la población. Las áreas verdes en la ciudad otorgan beneficios para el ambiente y la sociedad y son una necesidad básica del ser humano, al suministrar sombra, aportar oxígeno, controlar humedad ambiental, atenuar ruidos y vientos, retener partículas sólidas, permitir la recreación y contribuir con la mejora de la calidad de vida de los habitantes en las urbes (Gallegos, 2005). Además, las áreas verdes junto con el espacio público muestran y ponen al alcance de lugareños y foráneos lo que es el "carácter", la "personalidad" de una ciudad. Es enfatizar en que el Espacio Público en su acepción o categoría "efectivo" se constituye en lo que cualquier citadino puede considerar como la presencia de la ciudad.

El Área Metropolitana de la ciudad de Barranquilla, dentro de sus políticas de recuperación del medio ambiente, del saneamiento básico, la recreación, educación y la cultura, propone planes y programas que propenden por el mejoramiento de la calidad de vida de la población, en especial en aquellas zonas ubicadas en suelos de protección. Entre sus estrategias, esta la creación de proyectos que se constituyan en modelos para el desarrollo del área metropolitana (Decreto 0212 de 2014).

El diseño de un parque ecológico con carácter Metropolitano para la ciudad de Barranquilla y su área metropolitana, consiste en recuperar, aprovechar y transformar la inmensa zona que va a ser desocupada de los asentamientos humanos irregulares ubicados sobre un área de suelos de alto riesgo, para una extensa zona de gran valor ecológico y ambiental. La cual esta localizada al sur-occidente de la ciudad de Barranquilla con aproximadamente más de 300 hectáreas, y ubicado en los parques laderas No. 14, 13, 12 y 11, descritos en el nuevo Plan de Ordenamiento Territorial (POT) del Distrito Especial, Industrial y Portuario de Barranquilla 2012-2032, y plenamente identificadas en la cartografía G6-Estructura Ambiental del componente general del POT 2014.

El diseño de este parque ecológico con carácter metropolitano en la ciudad de Barranquilla, proveerá y propondrá una serie de servicios orientados básicamente hacia la creación de programas y acciones recreativas, 
educativas, culturales, y de turismo y preservación ecológica principalmente. Para lograr estos propósitos se ha proyectado en su concepción una serie de dotacionales como: zonas de juegos infantiles, zonas pasivas y activas, ciclo rutas, zonas de picnic y comederos, plazoletas, miradores ecológicos, bibliotecas, media torta, canchas múltiples para uso deportivo, y jardines con características especializadas en consideración al riesgo existente.

En una sociedad cada vez más congestionada y pese al carácter móvil y hostil de ella, la gente desea más estabilidad, en lo que el sentido de espacio es importante; y los parques, como representación de lugar, expresan valores personales y sociales, como una necesidad psicológica, un prerequisito social y un atributo espiritual (Barrios, 2010)

La falta de espacios públicos efectivos (Consejo Nacional de Política Económica y Social-Conpes, 2012), de encuentros y por ende recreacional en la ciudad y su área Metropolitana es significativa, prueba de ello es el indicador hallado en el POT 2000 que fue de menos de $1 \mathrm{mt}^{2} \times$ habitante, lo cual se encuentra muy por debajo a los estándares nacionales e internacionales. Entendiéndose como espacio público efectivo de la ciudad a las áreas requeridas para la recreación y reunión pública, de carácter permanente, conformado por zonas verdes, parques, plazas y plazoletas, activa o pasiva, las franjas de retiro de las edificaciones sobre las vías, fuentes de agua, las necesarias para la instalación y mantenimiento de los servicios públicos básicos, la instalación y uso de los elementos constitutivos del amueblamiento urbano en todas sus expresiones, para la preservación de las obras de interés público y de los elementos históricos, culturales, religiosos, recreativos y artísticos, para la conservación y preservación del paisaje y los elementos naturales del entorno de la ciudad, en general, por las zonas existentes o debidamente proyectadas en las que el interés colectivo sea manifiesto y conveniente y que constituyan por consiguiente zonas para el uso y disfrute colectivo.

La ubicación estratégica del Parque Ecológico Metropolitano de la ciudad de Barranquilla, hace posible ofertar a toda la población, sin distingo alguno, la ocasión de tener muy cerca espacios para el desarrollo físico-mental, individual y colectivo, que tienen como fundamento el disfrute de elementos naturales, en forma activa y pasiva, para su aprovechamiento en general por la población. 


\section{Justificación e impactos potenciales}

Mediante este artículo se propone el diseño de un "Parque Ecológico Metropolitano" para satisfacer las necesidades de los habitantes respondiendo a un problema real y social que afronta la ciudad de Barranquilla, en su área Metropolitana e incluso su influencia sobre la región inmediata.

Los retos que afrontan las grandes ciudades en cuanto a su equilibrio ambiental son sin duda de gran magnitud y relevancia; aunque al ser la ciudad un ecosistema incompleto heterótrofo, lo que quiere decir que no se puede considerar su equilibrio sin incluir los ambientes de entrada y salida, y que se demuestra que es un desastre entrópico para la estabilidad global del sistema terrestre, la contribución de la diversidad biótica establecida en el Parque Metropolitano, de la cantidad de materia vegetal, y del bajo impacto sobre el suelo (permeabilidad y baja agresión química) tiene un efecto sobre el ambiente urbano a considerar. Esta propuesta convertiría a este parque ecológico como el pulmón verde natural de mayor representación en toda la región.
Teniendo en cuenta el concepto de hecho metropolitano (POT, 2014) podemos establecer que son pocos los avances en cuantos proyectos presentados y ejecutados en la ciudad. Por tal razón es importante considerar diseñar un parque ecológico con carácter metropolitano para Barranquilla como proyecto modelo para toda la región Caribe, aprovechando la oportunidad que se plantea oficialmente a través del POT 2014, que señala el área de laderas para la propuesta de este tipo de actuaciones.

Los habitantes de la ciudad y del área metropolitana no cuentan en la actualidad con sitios o lugares públicos con estas características, en cuanto a la escala y carácter específicos, donde puedan disfrutar y realizar actividades al aire libre en grupos de amigos o familias aprovechando principalmente de un ambiente completamente sano donde prima el paisaje natural. A su vez este tipo de proyectos coadyuvaría a controlar el crecimiento urbanístico de la ladera y disminuir sus condiciones de inseguridad, limpiar el aire, proteger la biodiversidad, promover la integración urbana en espacios naturales, y proveer un escenario paisajístico adecuado para Barranquilla. 
Sería irónicamente "torpe" el pensar en la escasez de impactos no positivos que tuviera una intervención de este tipo sobre la estructura urbana del Distrito de Barranquilla. Tal vez, otras consideraciones acerca de la índole o capacidad portante o geológica de los suelos podrian representar un impacto negativo a los cuales son superables en la medida del respeto por la explotación no ecológica que se pueda vulnerar en las posibilidades del adecuado planteamiento de los elementos que estructuralmente contenga el futuro parque.

\section{Normas Jurídicas Urbano-Ambientales}

Las normas y principios ambientales consagrados en la Constitución Política de Colombia (1991) como "Derecho a un Ambiente Sano" son:

- Artículo 79. "Todas las personas tienen derecho a gozar de un ambiente sano. La ley garantizará la participación de la comunidad en las decisiones que puedan afectarlo. Es deber del Estado proteger la diversidad e integridad del ambiente, conservarlas áreas de especial importancia ecológica y fomentar la educación para el logro de estos fines".
- Artículo 80. "El Estado planificará el manejo y aprovechamiento de los recursos naturales, para garantizar su desarrollo sostenible, su conservación, restauración o sustitución. Además, deberá prevenir y controlar los factores de deterioro ambiental, imponerlas sanciones legales y exigir la reparación de daños causados"

- Artículo 88. "Consagra acciones populares para la protección de derechos e intereses colectivos para el medio ambiente, entre otros, bajo la regulación de la Ley".

\section{Normas}

\section{Generales-Ambientales}

- Decreto-Ley 2811 de 1974. Código Nacional de los Recursos Naturales renovables RNR y no renovables y de protección al medio ambiente. El ambiente es patrimonio común, el Estado y los particulares deben participar en su preservación y manejo. Regula el manejo de los RNR, la defensa del ambiente y sus elementos. 
- Ley 99 de 1993 crea el Ministerio del MedioAmbientey OrganizaelSistema Nacional Ambiental (SINA), reformando el sector público encargado de la gestión ambiental, organiza el sistema Nacional Ambiental y exige la Planificación de la gestión ambiental de proyectos. Los principios que se destacan y que están relacionados con la Ley 99 de 1993 son: La definición de los fundamentos de la política ambiental, la estructura del SINA, en cabeza del Ministerio del Medio Ambiente, los procedimientos de licenciamiento ambiental como requisito para la ejecución de proyectos o actividades que puedan causar daño al ambiente y los mecanismos de participación ciudadana en todas las etapas de desarrollo de este tipo de proyectos.

- Ley 388 de 1997 establece el Ordenamiento territorial municipal y distrital; plantea bases para los Planes de Ordenamiento Territorial y se resalta por parte del estado colombiano la importancia fundamental del Espacio Público como actuación urbanística

- Decreto 0212 de 2014. Por el cual se adopta el plan de ordenamiento territorial del distrito especial, industrial y portuario de Barranquilla 2012-2032
Artículo 275. Clasificación por escalas de los Parques. En el Distrito de Barranquilla, los aspectos a reglamentar para la clasificación de los parques, plazas, plazoletas y zonas verdes se hace a partir del área o superficie, el área o radio de influencia, la accesibilidad vehicular y peatonal, la población beneficiada y función ambiental y social que desempeña permitiendo una especialización en la definición tipológica. De acuerdo con su función y área, los parques se dividen en:

1. Parques Regionales y/o Metropolitanos. Zonas verdes o parques urbanos integrales, con una superficie superior a 100 hectáreas.

2. Parques Distritales. Zonas verdes o parques urbanos integrales, con una superficie superior entre $5 \mathrm{y}$ 10 hectáreas.

3. Parques Zonales. Son áreas libres, zonas verdes o parques con una superficie que varía entre 2 y 5 hectáreas.

4. Parques Locales. Zonas verdes o parques con una superficie inferior a 2 hectáreas. 
- Artículo 277. Normas específicas para el diseño de los parques.

Las normas específicas para el diseño de parques, en función de su escala. Parágrafo. Las disposiciones referentes a parques, en cualquiera de sus escalas, se complementa con lo señalado en el Manual del Espacio Público de Barranquilla y el Plan Maestro de Espacio Público, como instrumento reglamentario de Plan de Ordenamiento Territorial.
- Artículo 278. Actividades permitidas. De acuerdo con sus características y escala, en los parques se podrán desarrollar las actividades y usos enmarcados.

- Artículo 279. Actividades de recreación. De acuerdo con sus características y escala, en los parques se podrán desarrollar las actividades y usos enmarcados como actividades de recreación activa, recreación pasiva y área de juegos.

Fig. 1. Mapa Colombia.

Fuente: (c) google maps

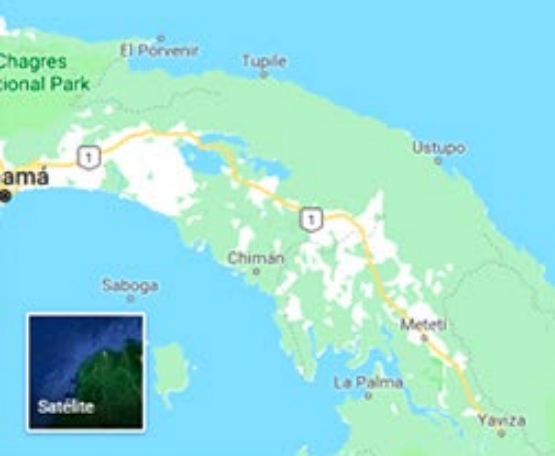




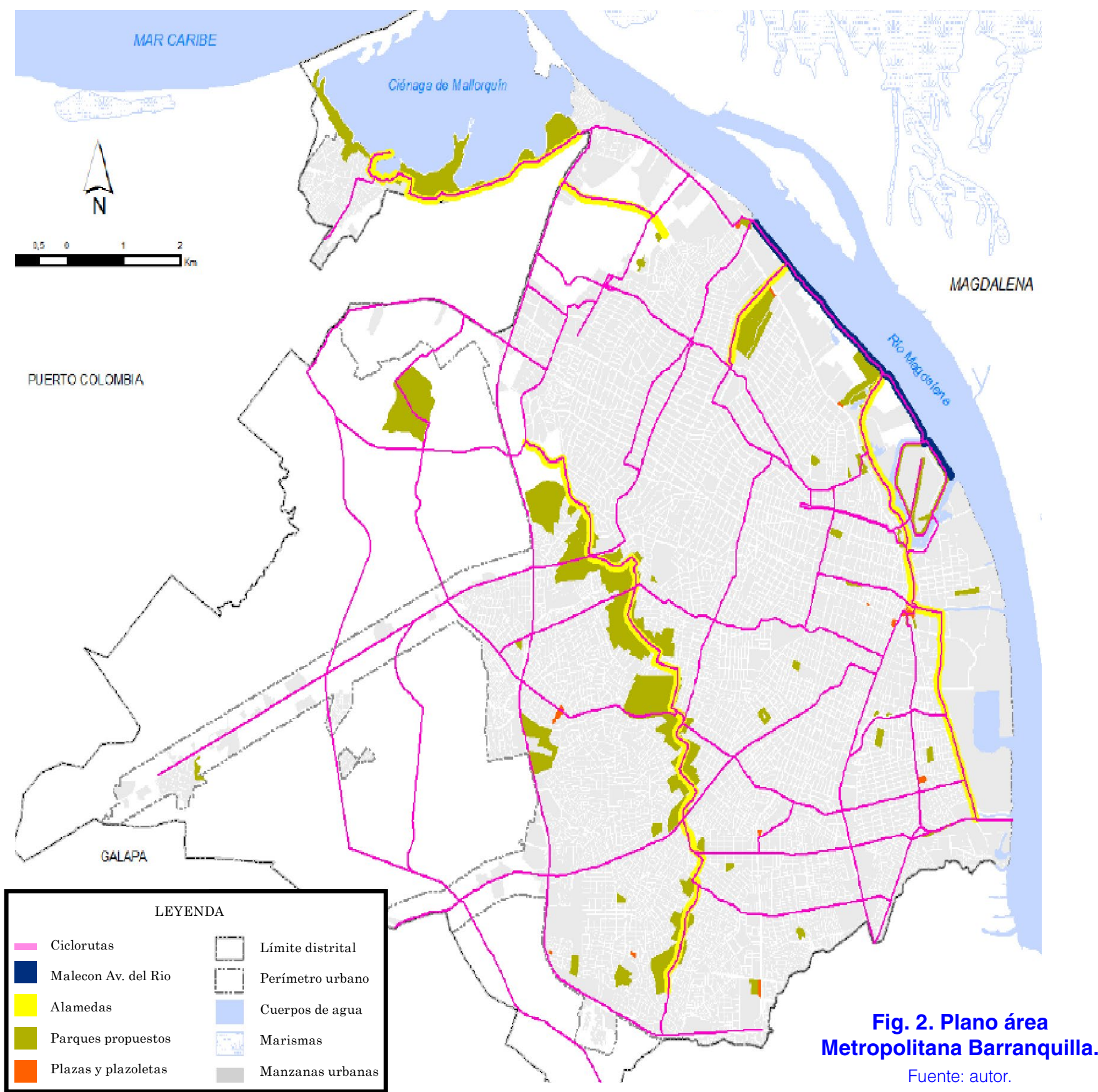



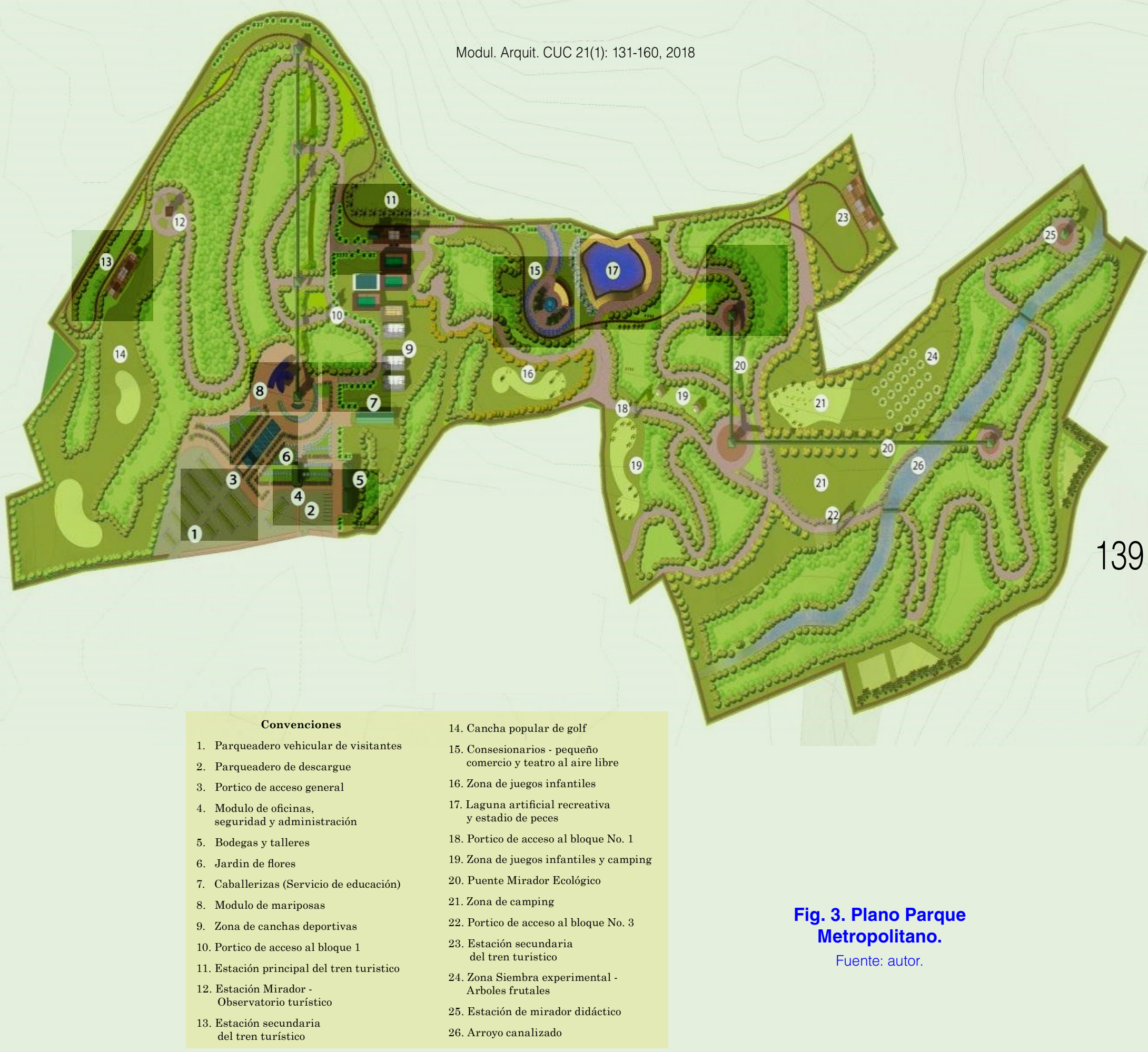

14. Cancha popular de golf

15. Consesionarios - pequeño comercio y teatro al aire libre

16. Zona de juegos infantiles

17. Laguna artificial recreativa y estadio de peces

18. Portico de acceso al bloque No. 1

19. Zona de juegos infantiles y camping

20. Puente Mirador Ecológico

21. Zona de camping

22. Portico de acceso al bloque No. 3

23. Estación secundaria del tren turistico

Fig. 3. Plano Parque Metropolitano.

24. Zona Siembra experimental Arboles frutales

25. Estación de mirador didáctico

26. Arroyo canalizado 

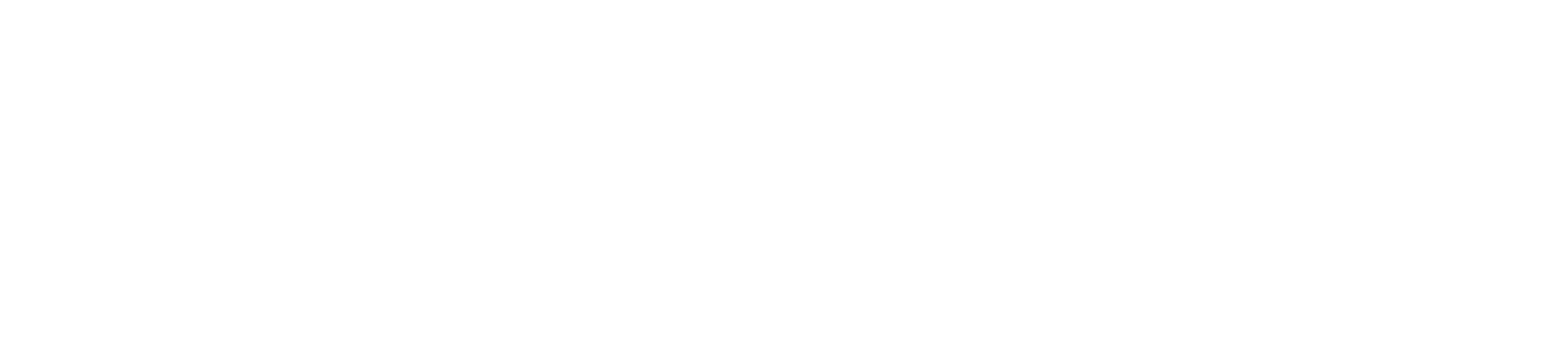

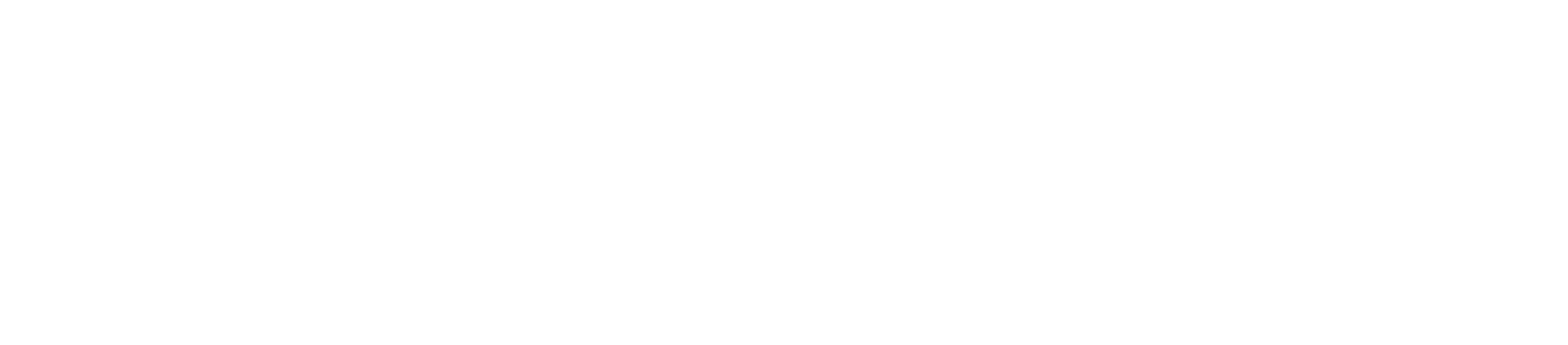

- (2*) Whe

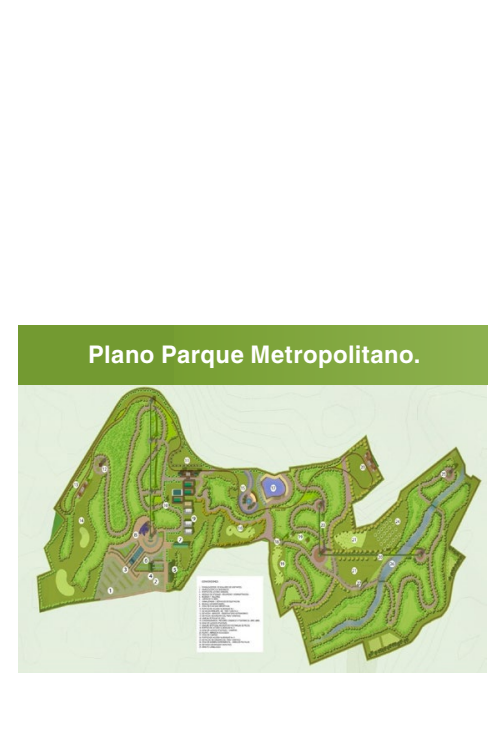
Fig. 5. Perspectiva del Fuente: autor.
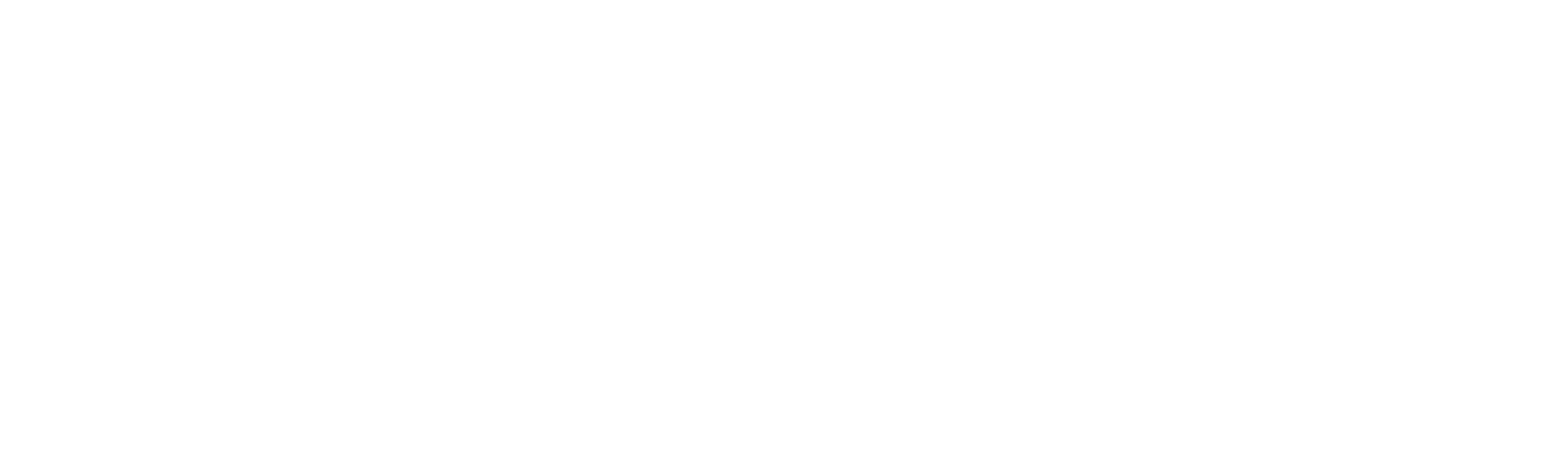

R.

an:
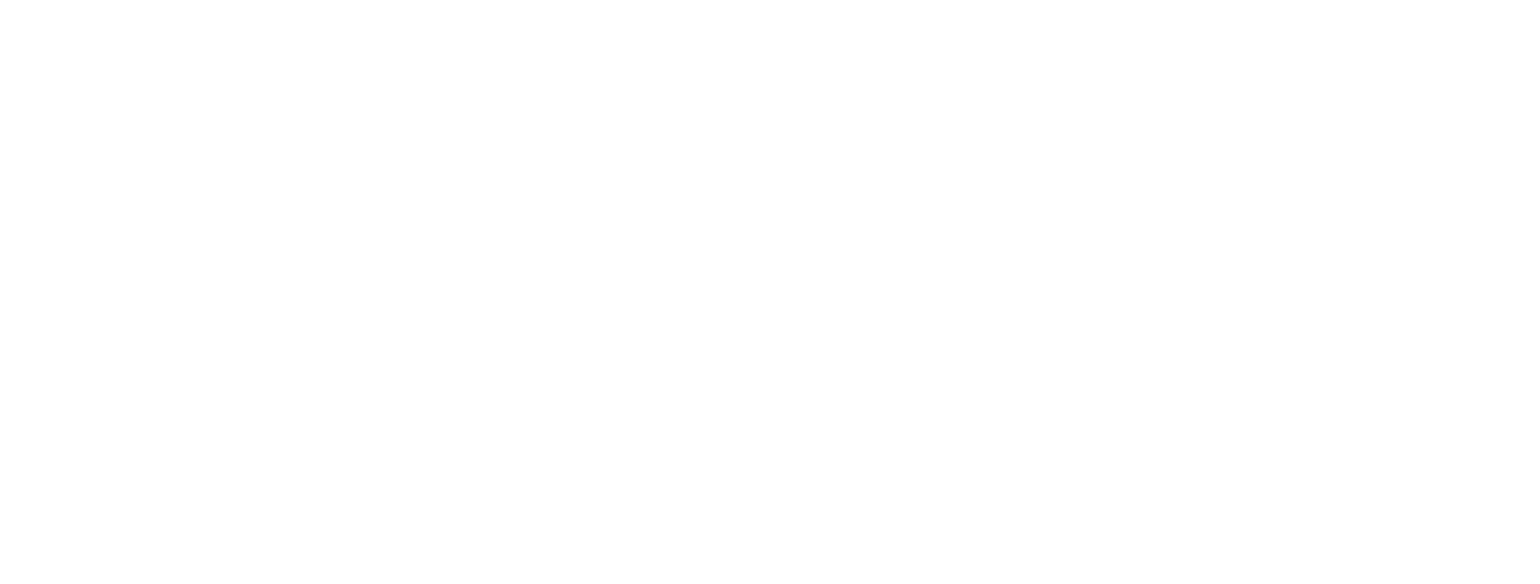

$x^{2}=12$
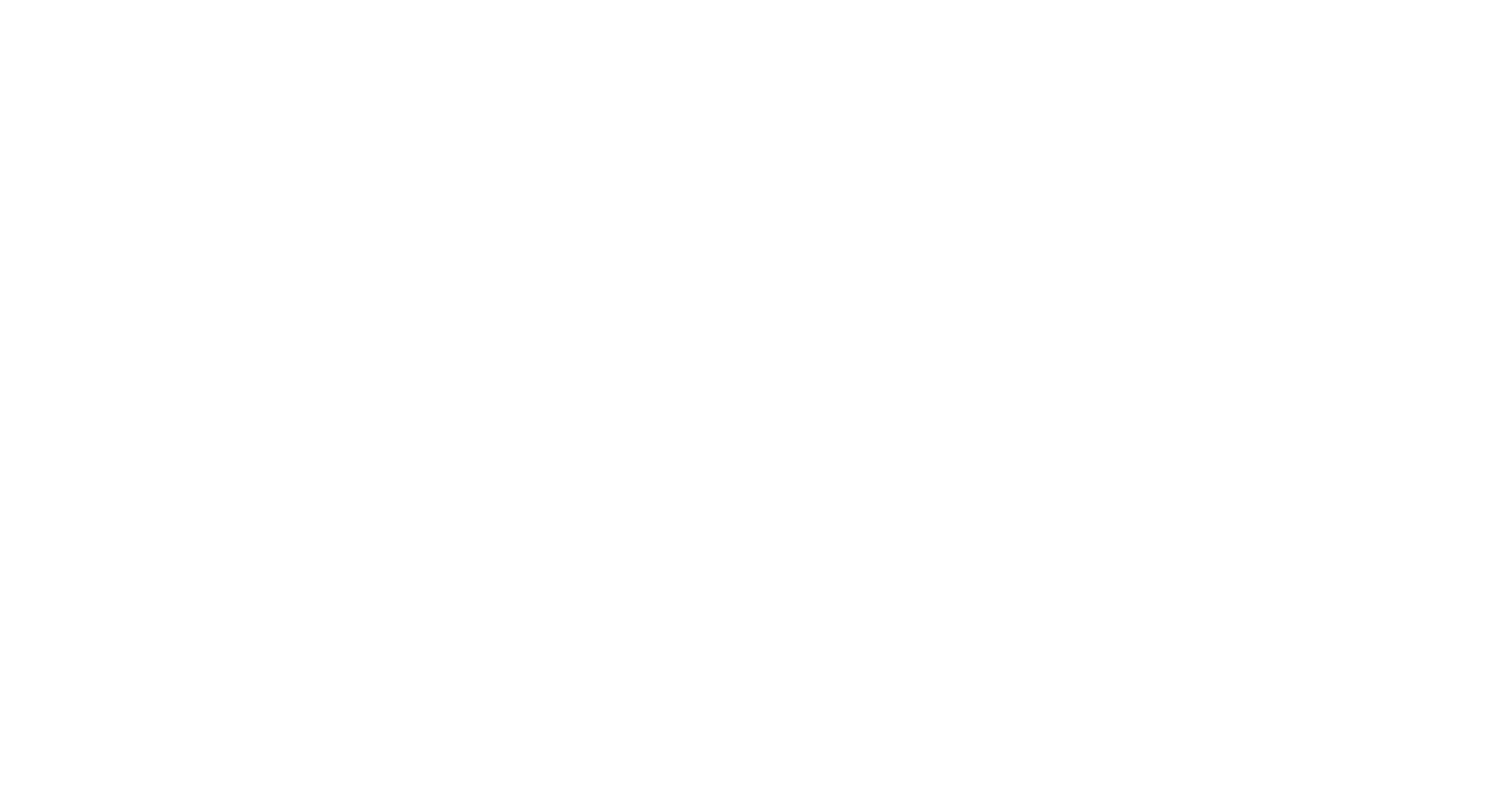


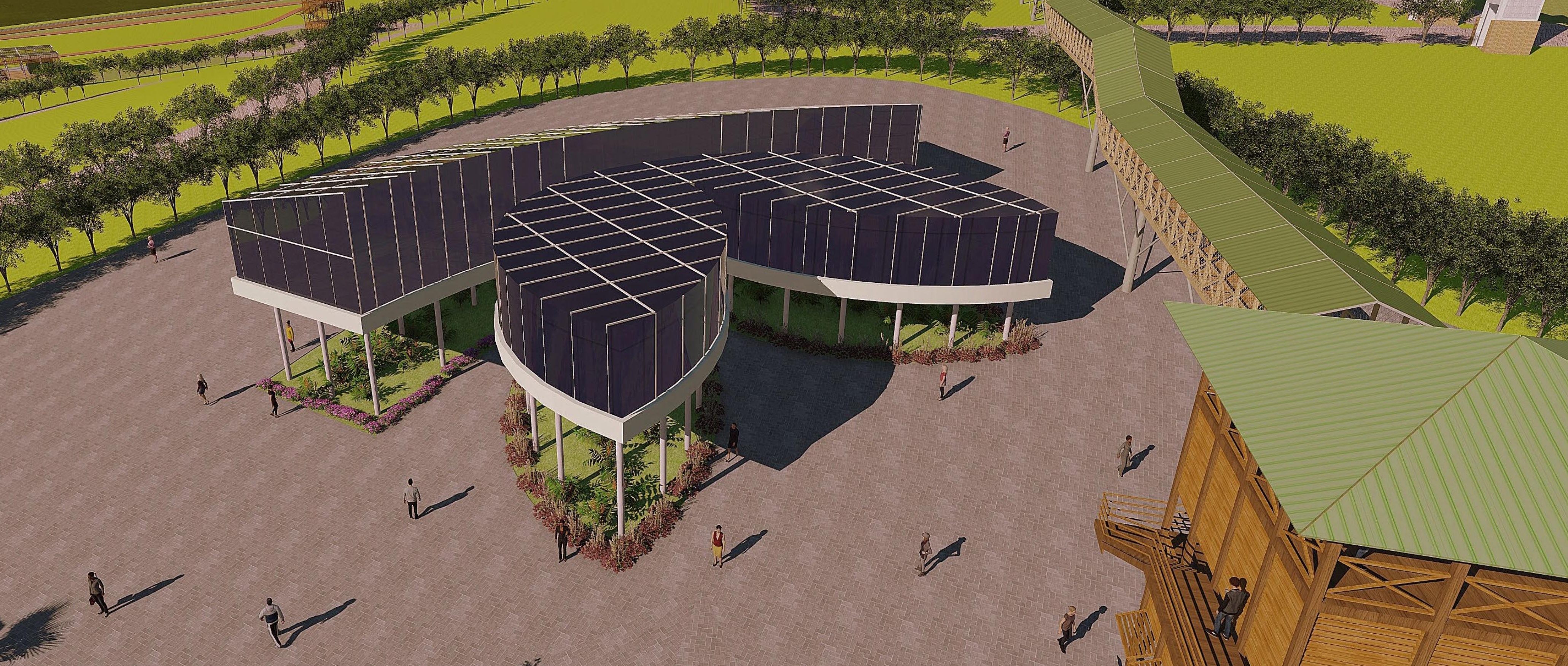




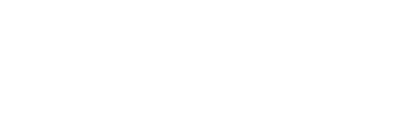

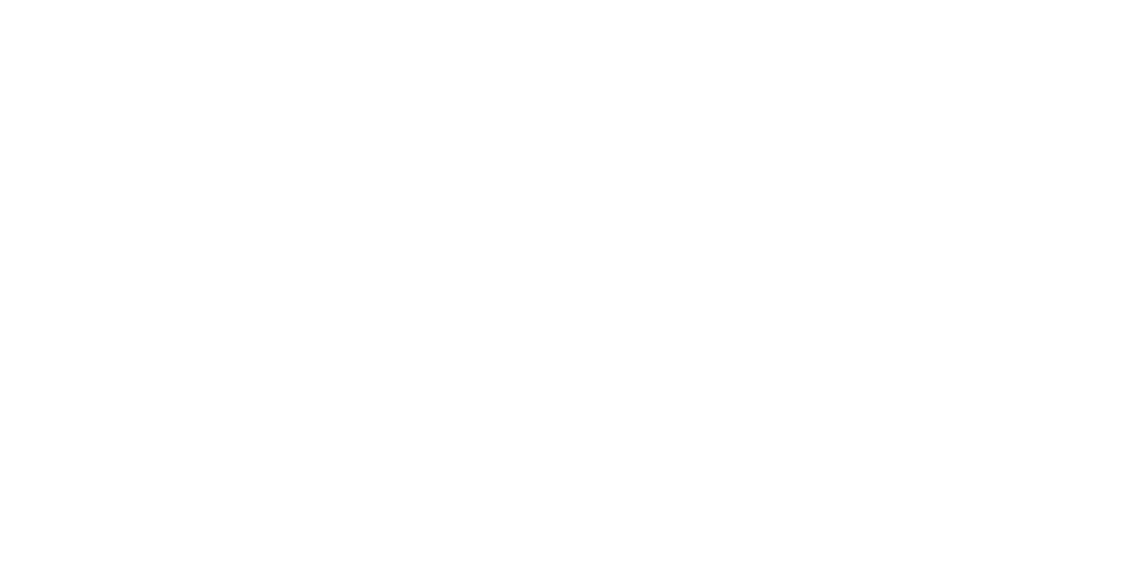

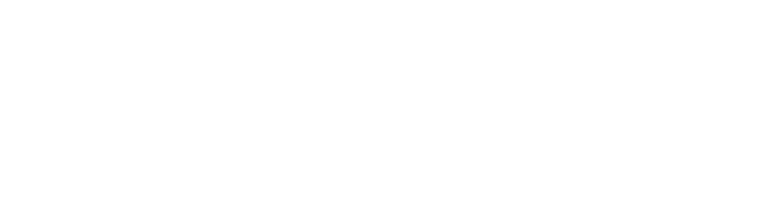

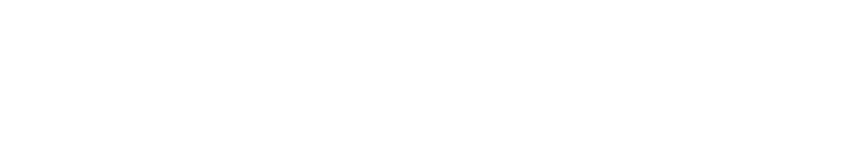

(3)

Sim
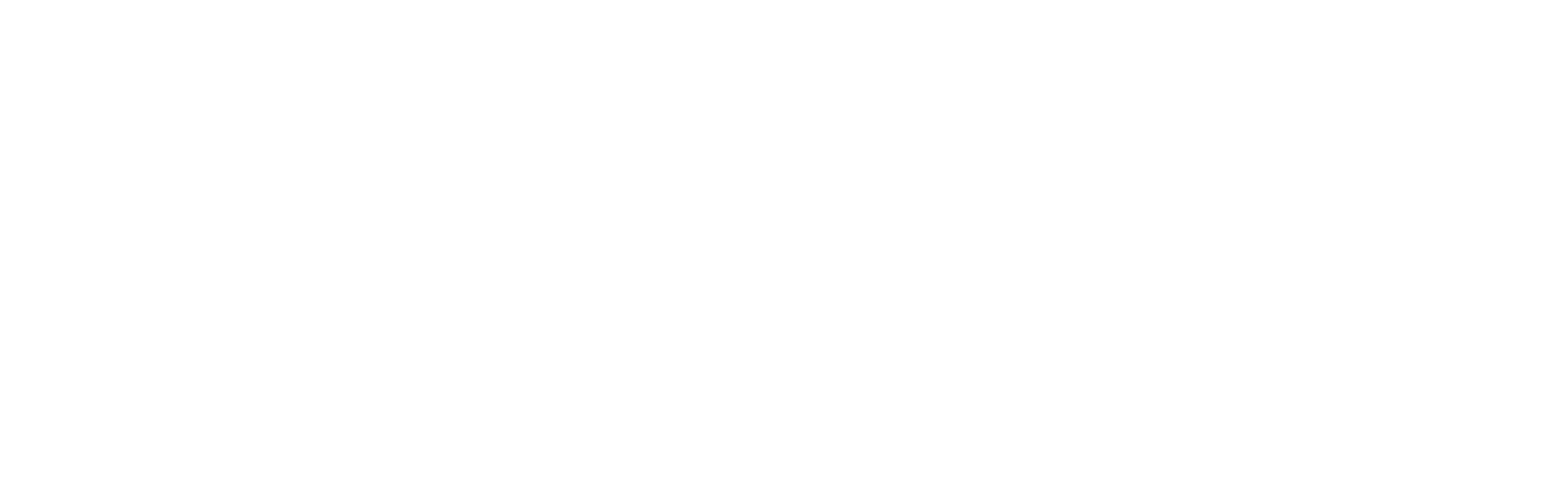

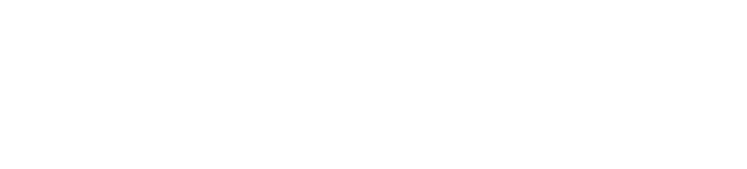
6. (in)

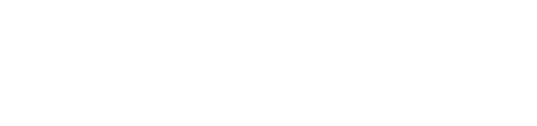
$4 x^{2}$ $x^{2}+2:$

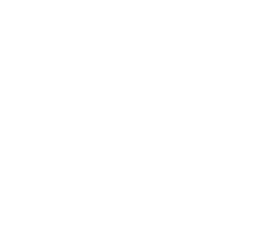




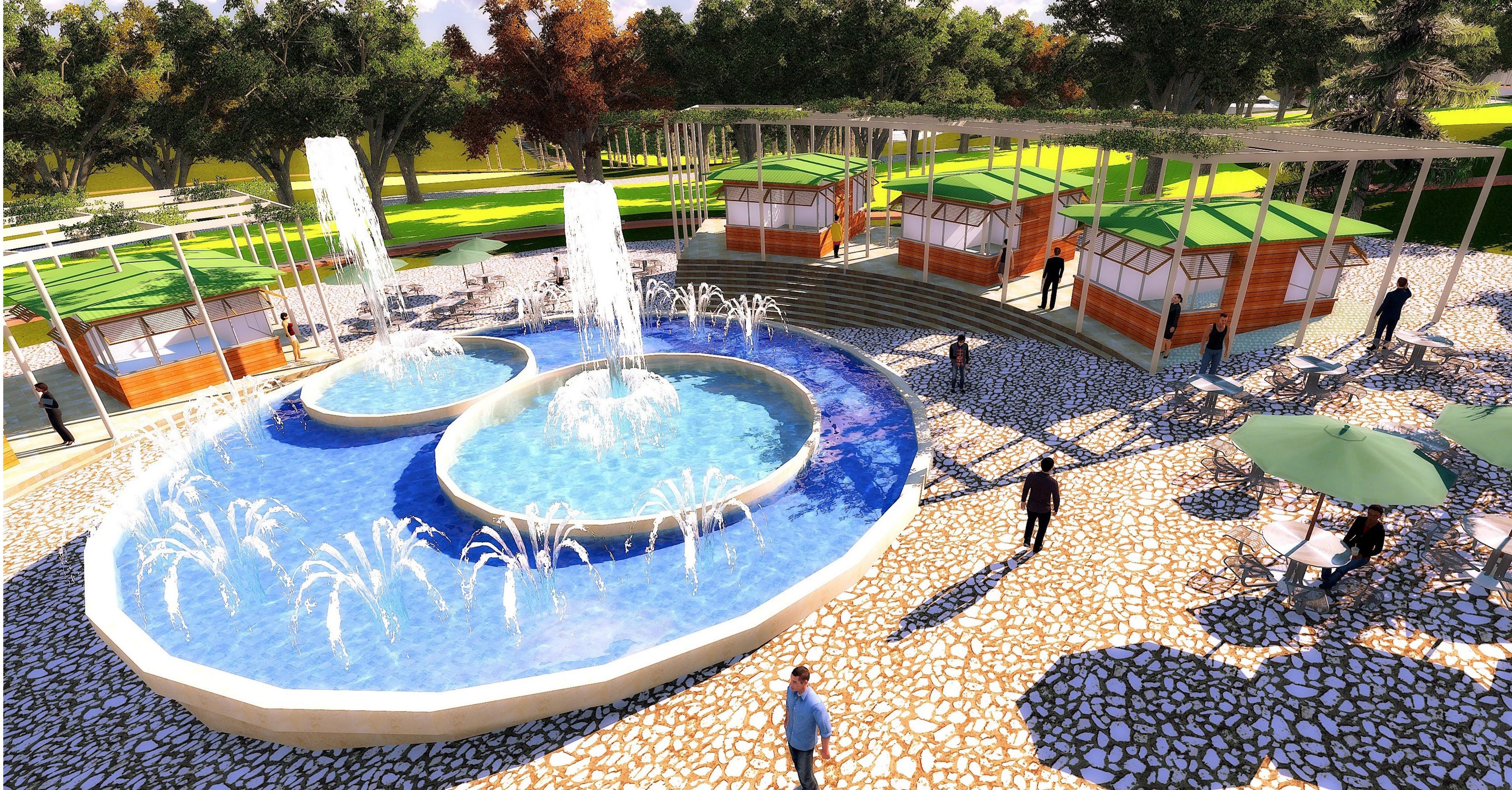



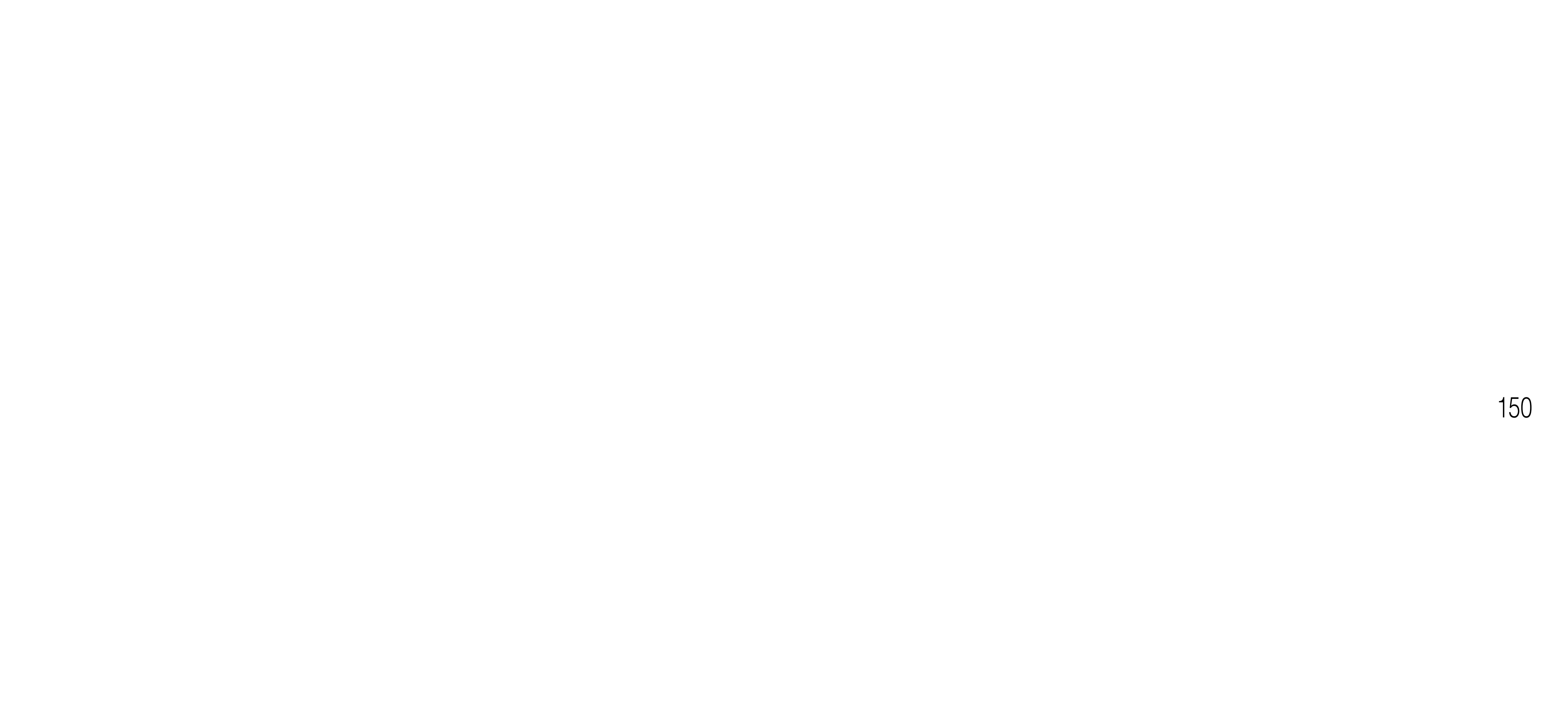


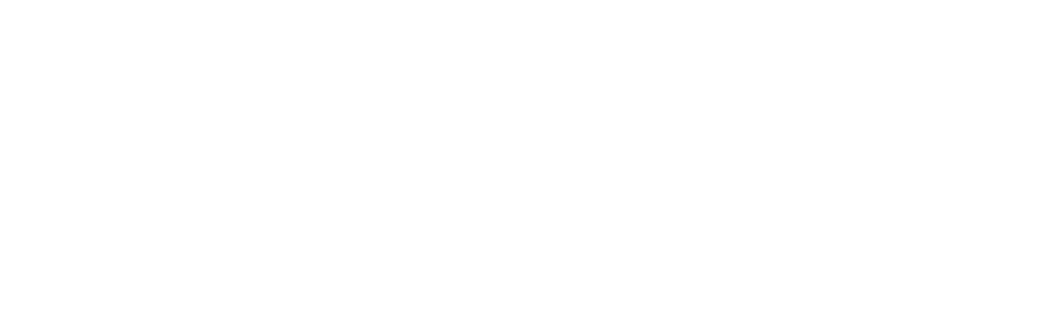

$$
x_{x+1}+4
$$
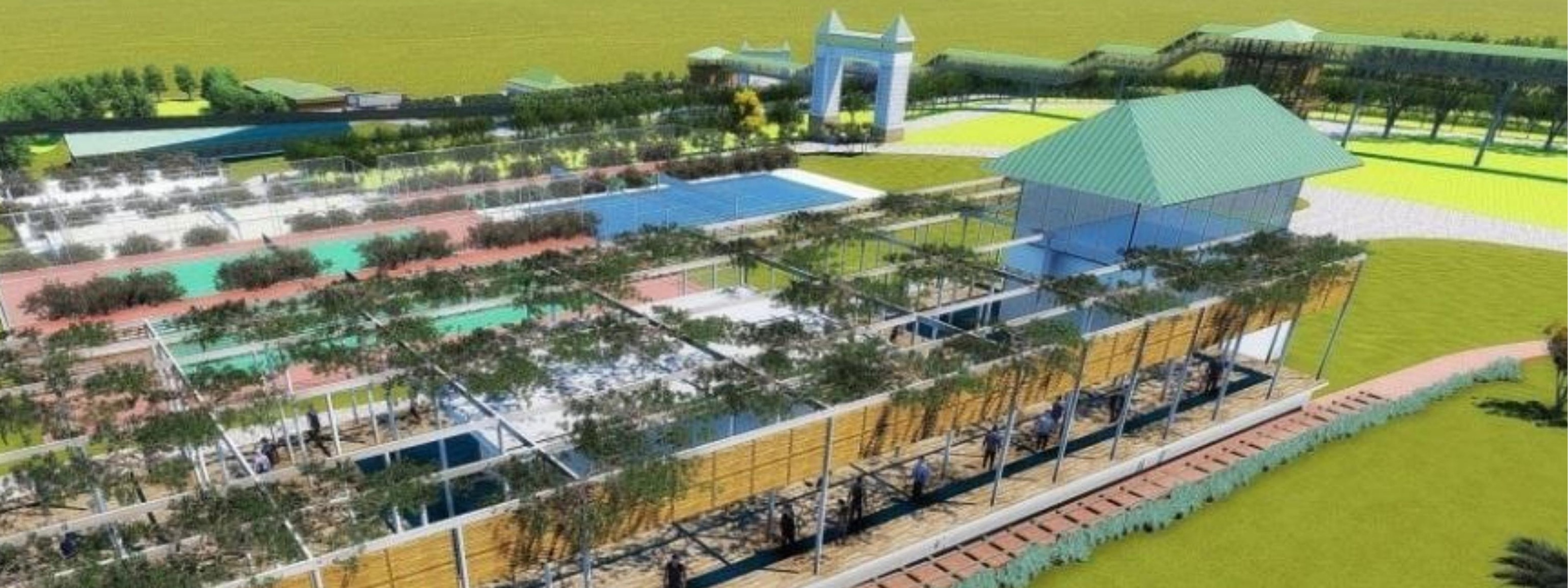

Vinesed.

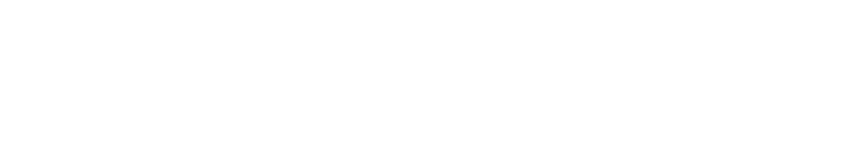

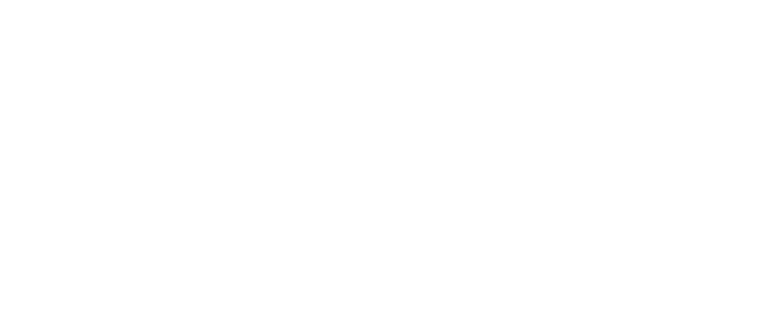

Huse

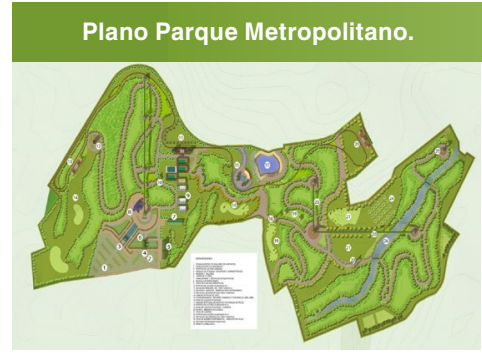

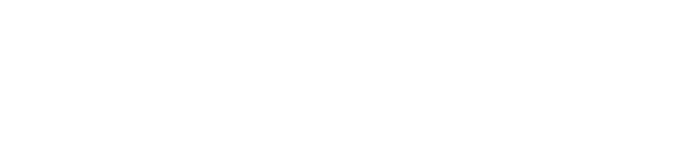

\section{is}

$x^{2}$

Fig. 10. Estacion del

tren eléctrico.
Fuente: autor.

\section{at}

\author{
एक
}

1)
4056 .
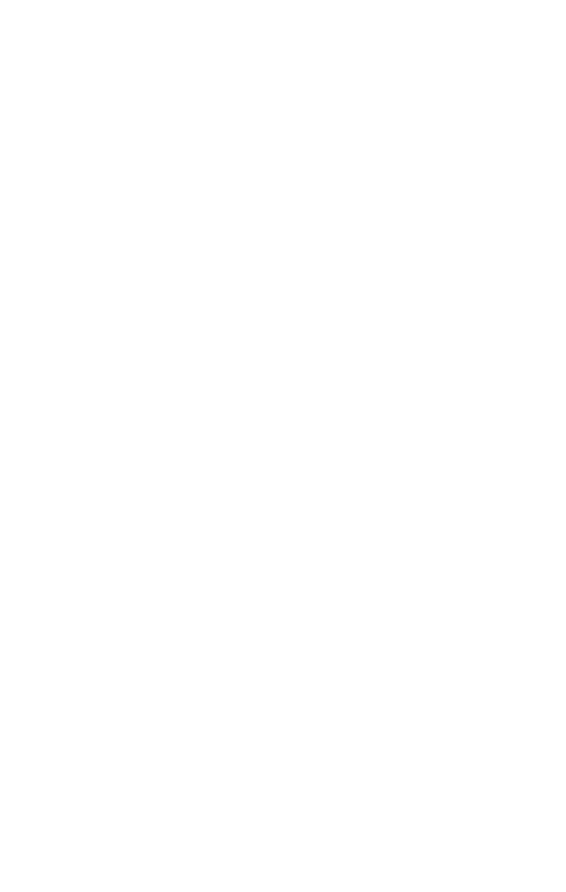

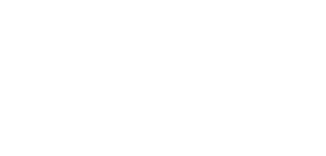

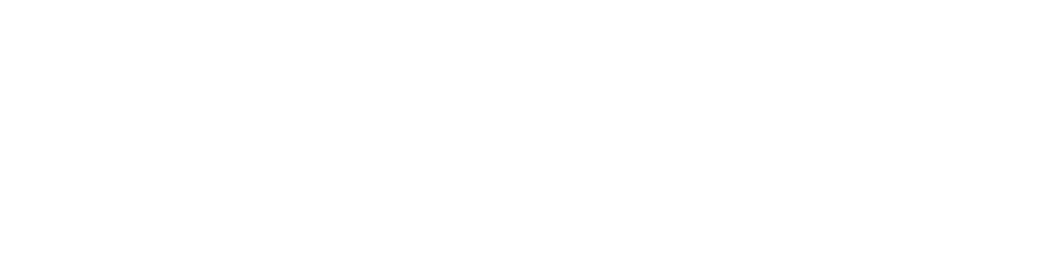

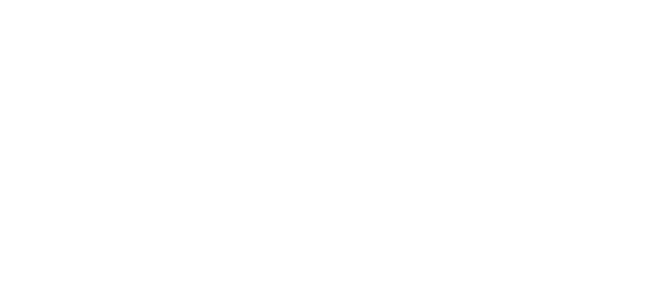

and
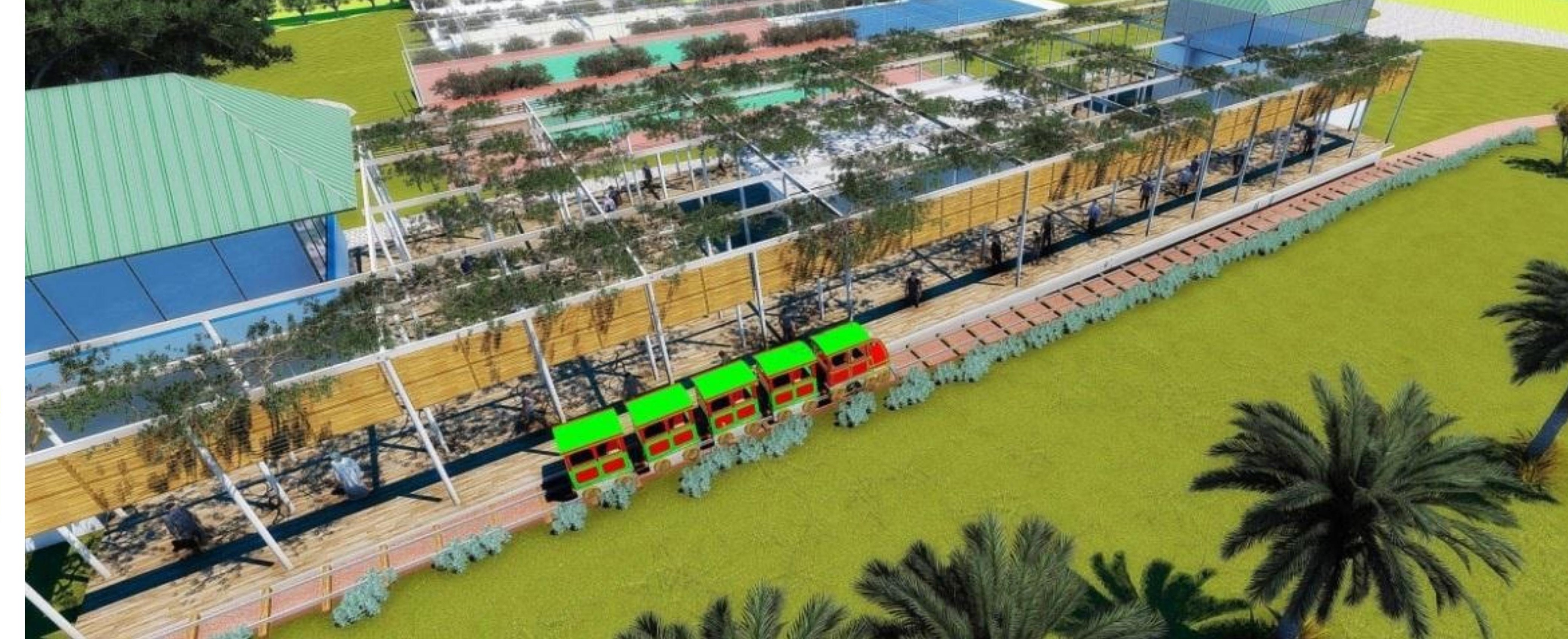

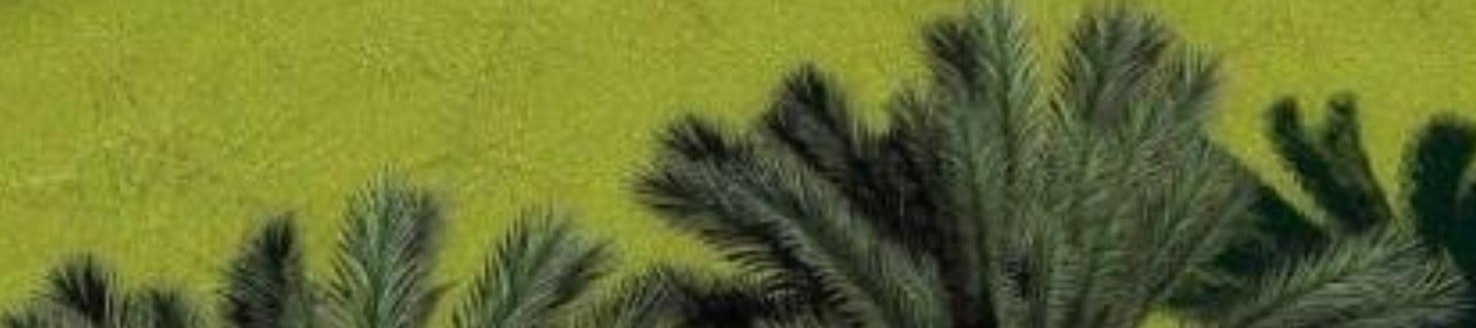




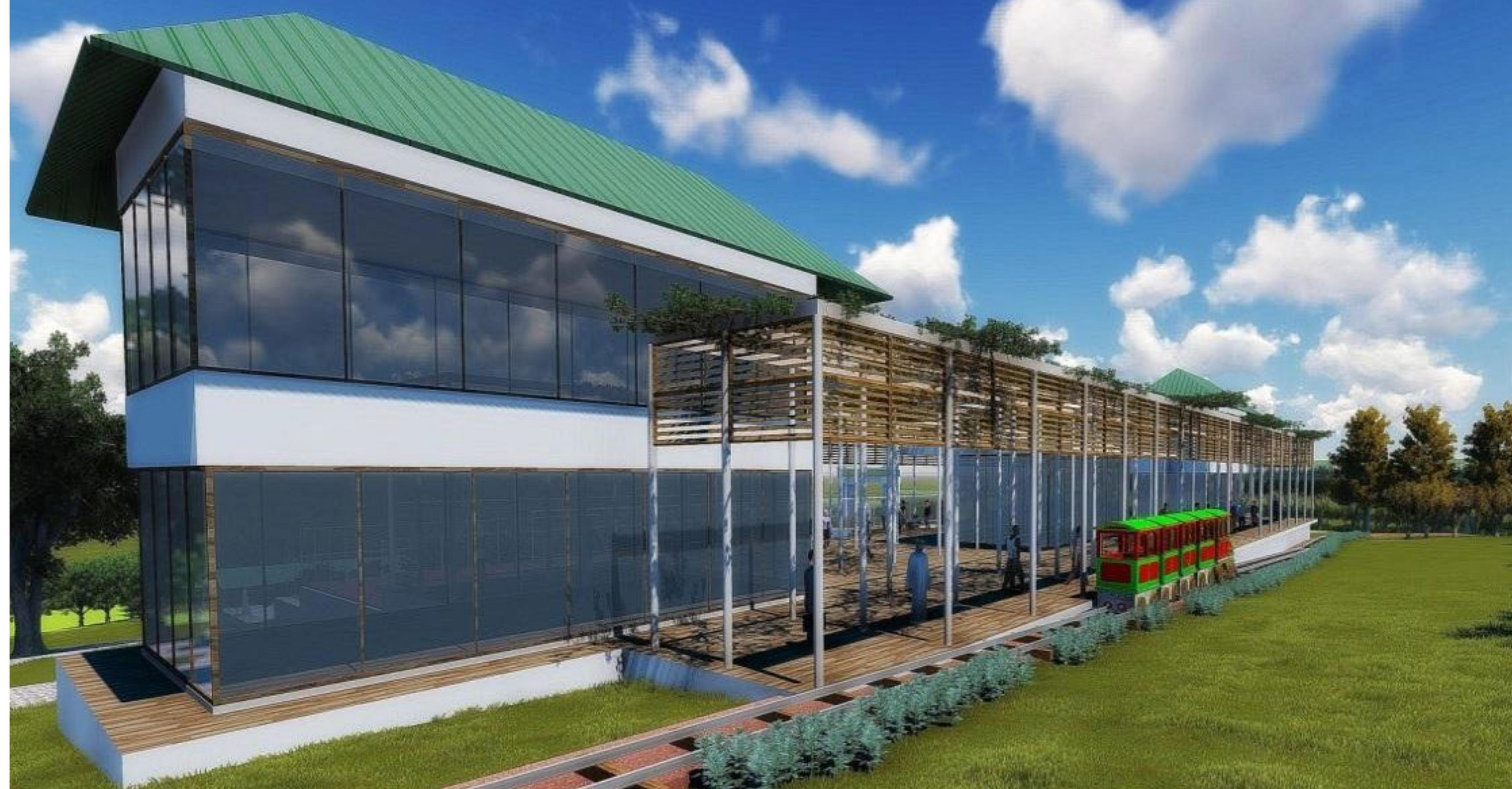




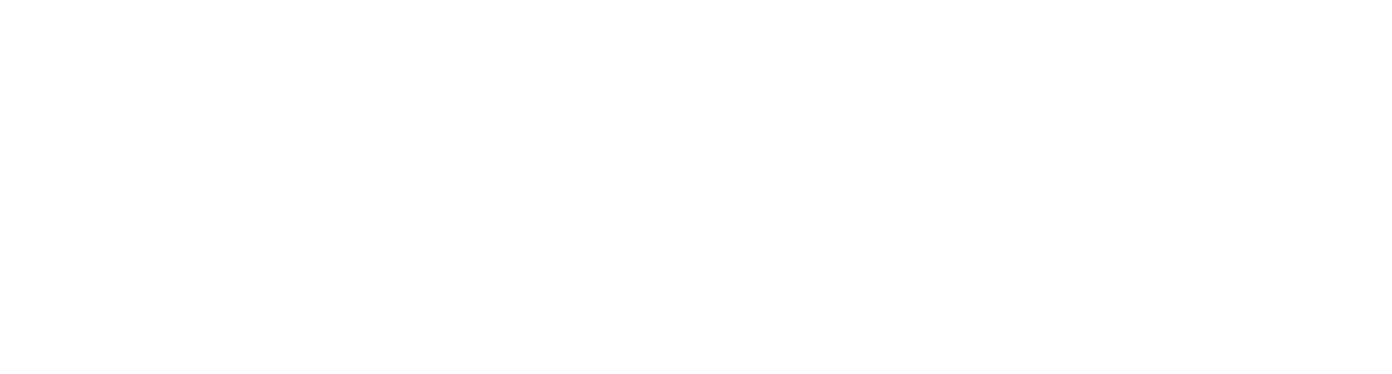

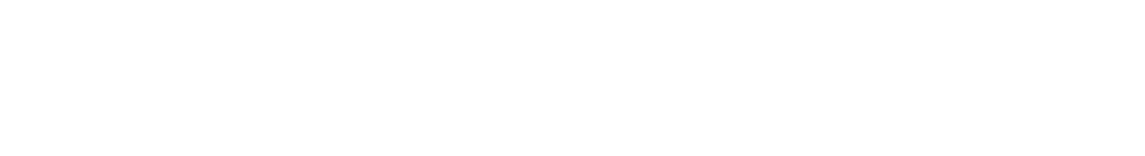

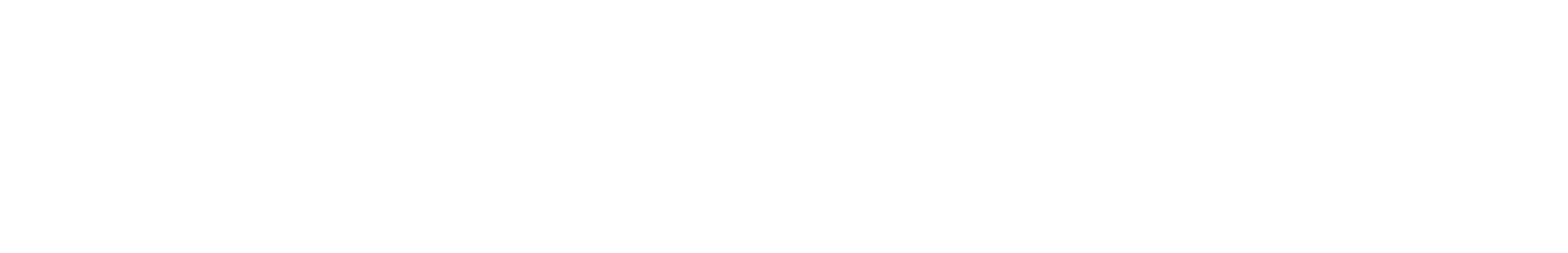

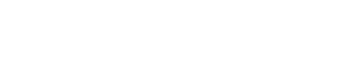
DA

26.

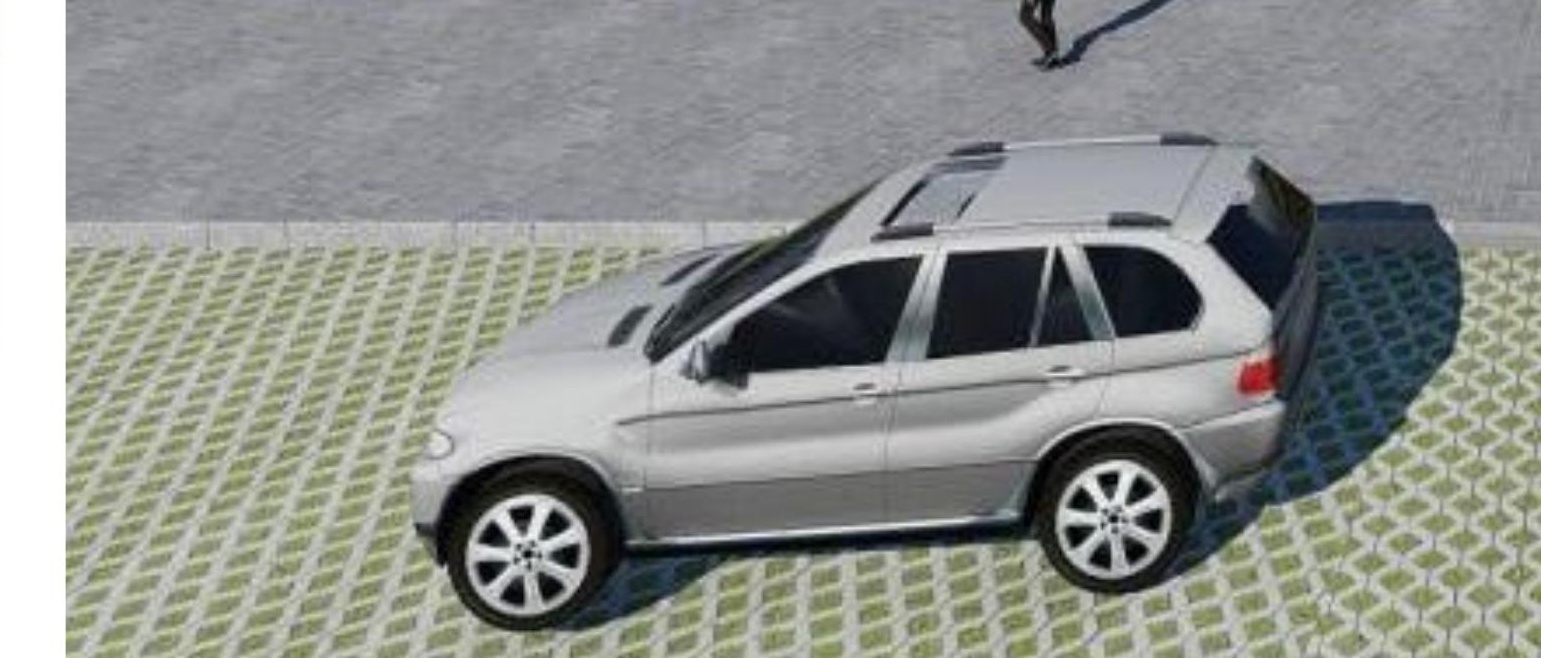

y

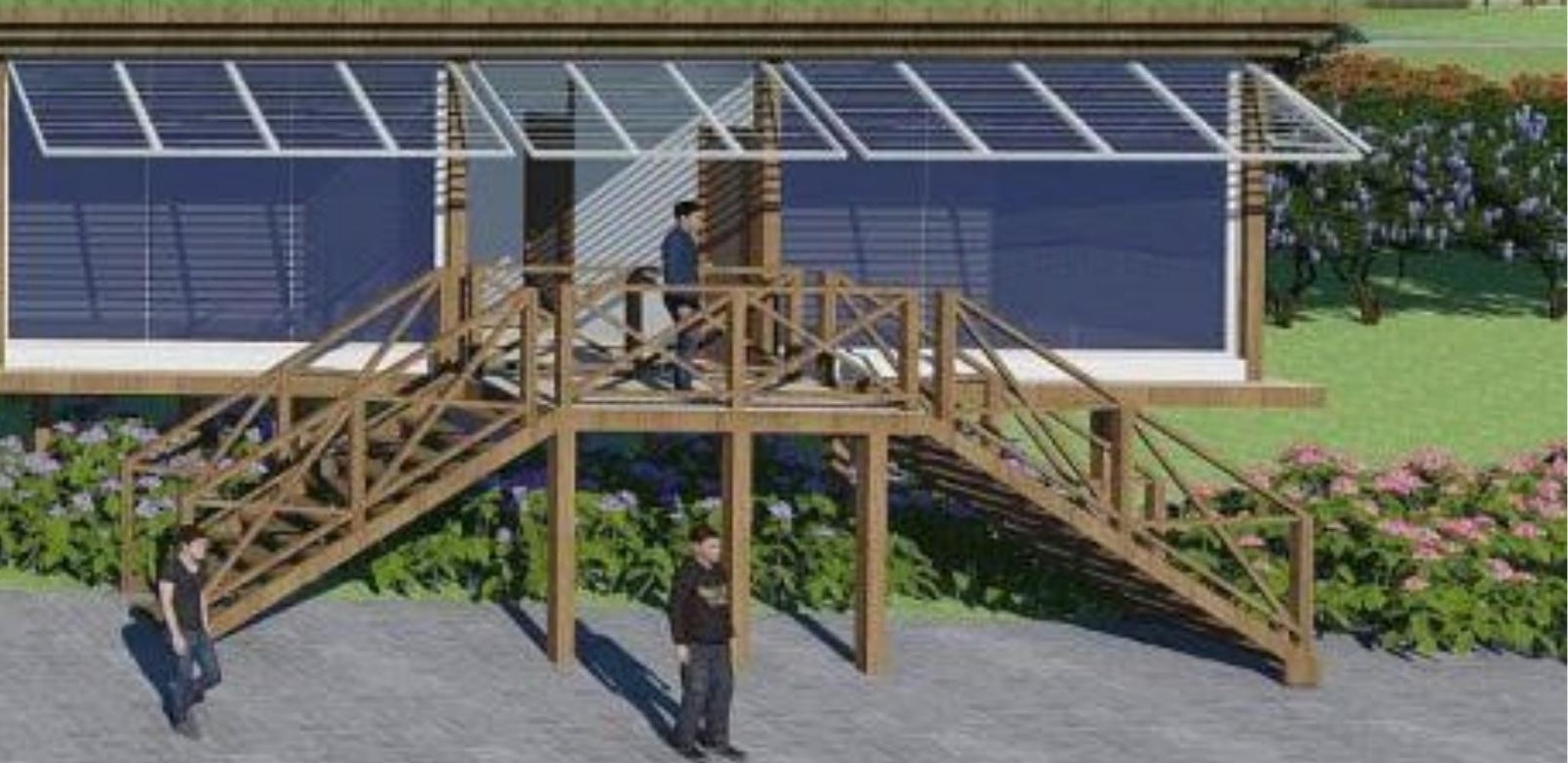

I 每 


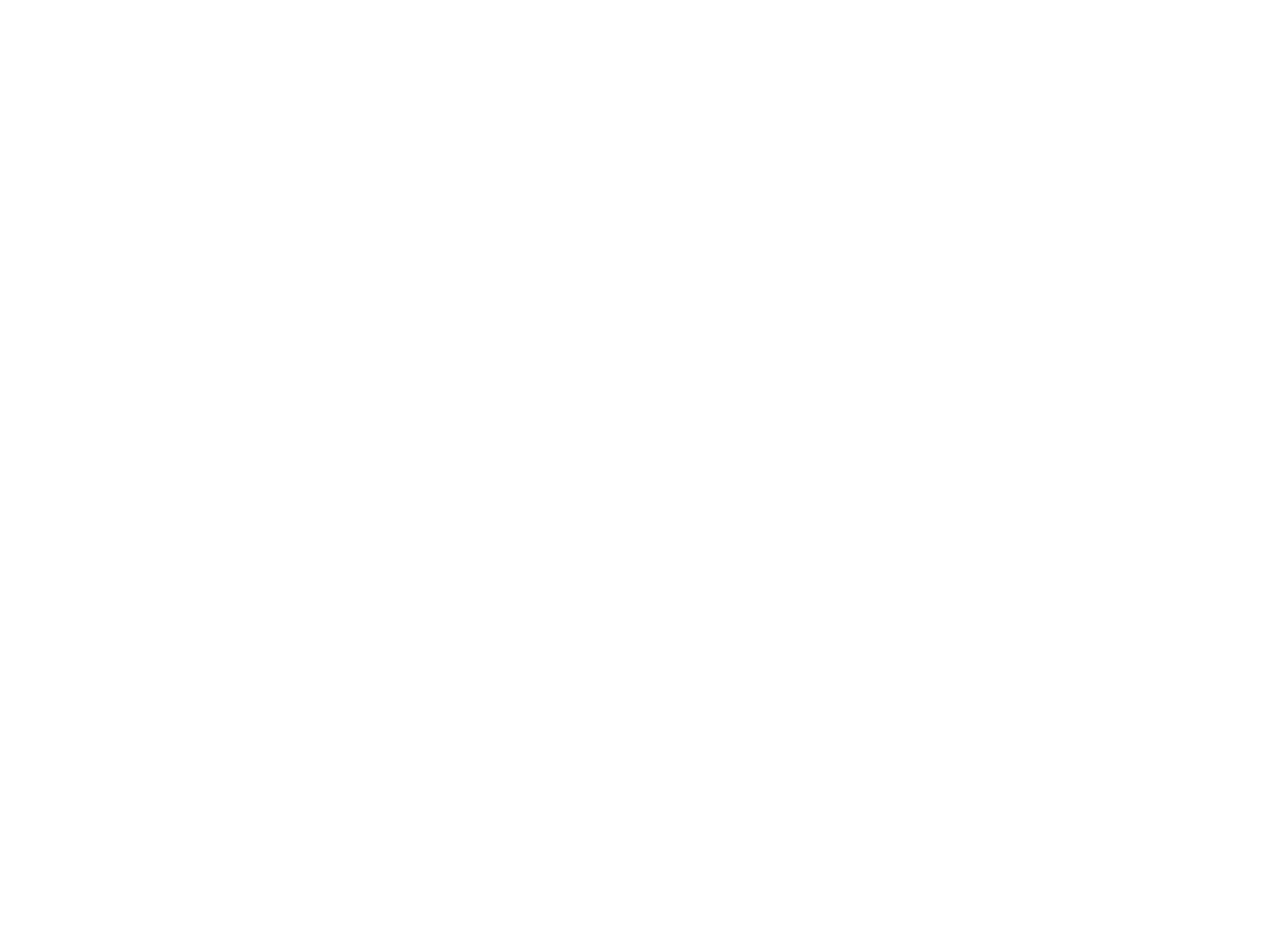

Una idea que parte de una de las acciones que resultaron delPOT 2014 adoptado para la ciudad de Barranquilla, es sin lugar a dudas el momento en que surge la idea de la concepción de formular un parque Mecidano emplazado en la zona suridea de re-asentar un grupo alto de familias y plantear programas y/o proyectos que fortalezcan y mejoren el espacio público efectivo. El sitio enclavado en una de áreas urbanas más difíciles y complejas de la estructura urbana pero no menos concebibles para su adecuada utilización que se gesta a partir de las ideas y cifras concretas que el POT 2000 arrojo desde esos tiempos: Barranquilla es una ciudad que "adolece" del índice adecuado de Espacio Público Verde que debe guardar en relación a volumen de población existente; solo menos de $1 \mathrm{~m}^{2}$ por habitante, cuando los estándares $y$ undias tiene un 7 mice de $12 \mathrm{~m}^{2}$ madamente La idea del diseño en cuestión debe favorecer no solo a los habitantes del Distrito sino del Área Metropolitana y hasta gran parte de la región Caribe Intrínsecamente este proyecto debe favorecer fomentar la transformación de la ciudad su perspectiva urbana principalmente. El interrogante planteado es la posibilidad de concebir y darle a ese espacio una utilidad que primero sea acorde a la naturaleza del sitio y segundo la idea de contribuir con una propuesta, carente no solo de un estandar como el anterior sino también de espacios ludilos adecurasosalvolum 
La Barranquilla del futuro necesariamente debe ser una ciudad que oferte dentro de sus posibilidades y escala, espacios para que su comunidad asentada y la de la región periférica tengan espacio que cumplan por lo menos con dos objetivos claros: Primero, mejorar la concepción ecológica de un medioambiente devastado desde hace muchas décadas y segundo, reforzar las posibilidades de generar proyectos de gran escala que permitan fortalecer y fomentar el espacio público que es como el marco físico-espacial, que hay que impulsar para lograr escenarios coherentes con su papel como la cuarta ciudad de Colombia.

\section{REFERENCIAS}

Alcaldía de Barranquilla. (2014). POT. Plan de Ordenamiento Territorial de Barranquilla. [Decreto 0212]. Recuperado de http://www.barranquilla.gov.co/publicaciones/cat_view/189-politicas-yplanes-institucionales/226-nuevoplan-de-ordenamiento-territorial/256decreto

Barrios, C. (2010). La situación medioambiental de los parques existentes en la ciudad de barranquilla. Revista Módulo, 1(9). 121-130.

Gallegos, L. (2005). Descripción y manejo de enfermedades en el arbolado urbano de la comuna de la Reina. [Tesis]. Universidad de Chile, Santiago. http://repositorio.uchile.cl/bitstream/ handle/2250/105066/gallegos_l. pdf?sequence $=3 \&$ is Allowed $=y$
República de Colombia. Conpes. (2012). Política General sobre el Espacio Público. [Conpes 3718]. Bogotá; D.C.: DNP.

República de Colombia. Asamblea Constituyente (jueves 4 de julio de 1991). Constitución Política de Colombia. Recuperado de http://www.corteconstitucional.gov.co/inicio/Constitucion\%20 politica\%20de\%20Colombia.pdf

República de Colombia. Congreso de la República. (18 de julio de 1997). Por la cual se modifica la Ley 9 de 1989, y la Ley 2 de 1991 y se dictan otras disposiciones. [Ley 388]. DO: 43.091. Recuperado de https://www.alcaldiabogota.gov.co/sisjur/normas/Norma1. jsp?i=339

República de Colombia. Congreso de la República. (22 de diciembre de 1993). Por la cual se crea el Ministerio del Medio Ambiente, se reordena el Sector Público encargado de la gestión y conservación del medio ambiente y los recursos naturales renovables, se organiza el Sistema Nacional Ambiental-SINA y se dictan otras disposiciones. [Ley 99]. DO: 44.188. Recuperado de https://normograma. info/men/docs/pdf/ley_0099_1993.pdf

República de Colombia. Presidencia de la República. (18 de diciembre de 1974). Código Nacional de Recursos Naturales Renovables y de Protección al Medio Ambiente. [Decreto 2811]. DO: 34.243. Recuperado de https:// www.icbf.gov.co/cargues/avance/ docs/decreto_2811_1974.htm 